\title{
Disrupted Pancreatic Exocrine Differentiation and Malabsorption in Response to Chronic Elevated Systemic Glucocorticoid
}

Karen Wallace, Paul A. Flecknell, Alastair D. Burt, and Matthew C. Wright

From the Institute of Cellular Medicine, Newcastle University, Newcastle Upon Tyne, United Kingdom

Glucocorticoids are antiinflammatory therapeutics that have potent effects on cell differentiation. The aim of this study was to establish whether systemic glucocorticoid exposure significantly affects pancreatic differentiation in vivo because hepatocyte-like cells have been documented to occur in the diseased rodent pancreas. Expression of hepatic markers was examined in pancreata from mice genetically modified to secrete elevated circulating endogenous glucocorticoid $[\mathrm{Tg}(\mathrm{Crh})]$. $\mathrm{Tg}(\mathrm{Crh})$ mice with elevated glucocorticoid appeared cushingoid and by 21 weeks of age were obese, insulin-resistant, and had extensive areas of hepatic gene expression in exocrine tissue. Acinar cells from $\mathrm{Tg}(\mathrm{Crh})$ mice costained for both amylase and cyp2e1, suggesting direct acinar-hepatic transdifferentiation. Hepatic expression increased with age in the pancreas to such an extent that malabsorption and rapid weight loss occurred in a subset of aging mice; this effect was reversed by dietary porcine pancreatic enzyme supplementation. Indeed, pancreatic expression of hepatic markers was prevented by adrenalectomy, establishing a direct role for glucocorticoid. Elevated levels of circulating glucocorticoid therefore promote a transdifferentiation of adult exocrine pancreas into hepatocyte-like cells, and chronic exposure results in pancreatic malfunction. Glucocorticoids are thus capable of modulating the differentiation of terminally differentiated adult cells. (Am J Pathol 2010, 177:1225-1232; DOI: 10.2353/ajpath.2010.100107)

Pancreatic damage or ectopic expression of growth factors in rodents results in the appearance of hepatocytelike cells within the exocrine pancreas. ${ }^{1-4}$ The origin of these cells has not been established, but it has been suggested that progenitor cells in the ductal region of the pancreas may differentiate toward an hepatic lineage in the abnormal damaged/diseased environment. ${ }^{5}$ The propensity for pancreatic-hepatic transdifferentiation is likely associated with the close embryological relationship, the major cells in both tissues being derived from the embryonic endoderm. ${ }^{6}$

It has recently been shown that pancreatic exocrine cells can transdifferentiate into endocrine cells in vivo without reversion to a plastic precursor through the ectopic expression of several transcription factors. ${ }^{7,8}$ The significance of this response is that it suggests that pancreatic acinar cells may be amenable to direct transdifferentiation to other cell types if the appropriate transcription factor profile is expressed. Because pancreatic exocrine cells have been shown to differentiate into hepatocyte-like cells in vitro in response to glucocorticoid exposure, ${ }^{9}$ we hypothesized that this may be a pathophysiological response of the acinar cells in vivo to elevated levels of glucocorticoid in vivo.

Glucocorticoids are a class of steroid hormone secreted from the adrenal gland that regulate metabolism, promoting the catabolism of cellular constituents (eg, amino acids). ${ }^{10}$ Nonphysiological elevated levels of systemic glucocorticoids also inhibit inflammation, ${ }^{11}$ which is used therapeutically in the treatment of a range of chronic inflammatory diseases, including ulcerative colitis, ${ }^{12}$ Crohn's disease, ${ }^{13}$ asthma, ${ }^{14}$ autoimmune hepatitis, ${ }^{15}$ rheumatoid arthritis, ${ }^{16}$ and others. We have recently demonstrated that treating rats for 25 days with the synthetic glucocorticoid dexamethasone resulted in the occasional appearance of exocrine cells expressing hepatic mark-

Supported by a grant from the University of Newcastle. K.W. is supported by Biotechnology and Biological Sciences Research Council Ph.D. Strategic Studentship award.

Accepted for publication May 17, 2010

Supplemental material for this article can be found on http://ajp. amjpathol.org.

Address reprint requests to Dr. Matthew Wright, Ph.D., Institute of Cellular Medicine, Level 2 William Leech Building, Medical School, Framlington Place, Newcastle University, Newcastle Upon Tyne, NE2 4HH UK. E-mail: M.C.Wright@ncl.ac.uk. 
Table 1. DNA Oligonucleotide Sequences Used in RT-PCR or PCR Genotyping

\begin{tabular}{|c|c|c|c|}
\hline Oligo ID & Sequence & $\begin{array}{l}\text { Annealling } \\
\text { conditions }\end{array}$ & Comments \\
\hline \multicolumn{4}{|l|}{ RT-PCR } \\
\hline mcyp2eUS & 5'-GTGTTCCGAGGATATGTCATC-3' & $43^{\circ} \mathrm{C}$ & Will amplify mouse cyp2e1 (NM_021282.2) cDNA \\
\hline mcyp2eDS & 5'-AAAGCAGAAACAGTTCCATGCG-3' & & sequence of $223 \mathrm{bp}$ \\
\hline mcyp3a25US & $5^{\prime}-$ TCAAGGAGATGTTCCCCATC- $3^{\prime}$ & $58^{\circ} \mathrm{C}$ & Will amplify mouse cyp3a25 (NM_019792.1) cDNA \\
\hline mcyp3a25DS & $5^{\prime}$-CTTCTGGTTTGAAGCAAGGC-3' & & sequence of $374 \mathrm{bp}$. \\
\hline mCPS-IUS & 5'-GGCTGGCTACCAAGAGTCTG-3' & $58^{\circ} \mathrm{C}$ & Will amplify mouse CPS-I (NM_001080809.1) cDNA \\
\hline mCPS-IDS & $5^{\prime}$-GCTTAACTAGCAGGCGGATG-3' & & sequence of $285 \mathrm{bp}$. \\
\hline malbuminUS & 5'-TGCTGCTGATTTTGTTGAGG-3' & $55^{\circ} \mathrm{C}$ & Will amplify mouse albumin (NM_009654.3) cDNA \\
\hline malbuminDS & 5'-AGAGTTGGGGTTGACACCTG-3' & & sequence of $354 \mathrm{bp}$. \\
\hline $\begin{array}{l}\text { mamylaseUS } \\
\text { mamylaseDS }\end{array}$ & $\begin{array}{l}\text { 5'-GGGAGGACTGCTATTGTCCA-3' } \\
\text { 5'-CATTGTTGCACCTTGTCACC-3' }\end{array}$ & $55^{\circ} \mathrm{C}$ & $\begin{array}{l}\text { Will amplify mouse pancreatic amylase 2a2 } \\
\text { (NM_001160152.1), 2a3 (NM_001160151.1), 2a4 } \\
\text { (NM_001160150.1), and 2a5 (NM_001042711.2) } \\
\text { cDNA sequences of } 241 \mathrm{bp} \text {. }\end{array}$ \\
\hline rmhGAPDHUS & 5'-TGACATCAAGAAGGTGGTGAAG-3' & $50^{\circ} \mathrm{C}$ & Will amplify rat (NM_017008), human (NM_002046), or \\
\hline rmhGAPDHDS2 & 5'-TCTTACTCCTTGGAGGCCATGT-3' & & $\begin{array}{l}\text { mouse (NM_008084) glyceraldehyde } 3 \text { phosphate } \\
\text { dehydrogenase cDNA sequence of } 243 \mathrm{bp} \text {. }\end{array}$ \\
\hline $\mathrm{rm} \beta 1 \mathrm{CATENINUS}$ & 5'-CTGACCAGTTCCCTCTTCA-3' & $42^{\circ} \mathrm{C}$ & Will amplify rat (NM_053357) and mouse (NM_007614) \\
\hline $\mathrm{rm} \beta 1 \mathrm{CATENINDS}$ & 5'-ССАТСTCATGCTCCATCATA-3' & & cDNA sequences of $187 \mathrm{bp}$ \\
\hline rCRHUS & 5'-AGGTACCTCGCAGAACAACA-3' & $58^{\circ} \mathrm{C}$ & Will amplify rat (NM_031019.1) cDNA sequence of 202 \\
\hline rCRHDS & 5'-GGTTGCAAGAAATTCAACGG-3' & & $\begin{array}{l}\text { bp. Selective for rat sequence over mouse orthologue } \\
\text { (NM_205769.1) - see Supplemental Figure } 1 \text { available } \\
\text { at } h \text { ttp://ajp.amjpathol.org. }\end{array}$ \\
\hline \multicolumn{4}{|r|}{ 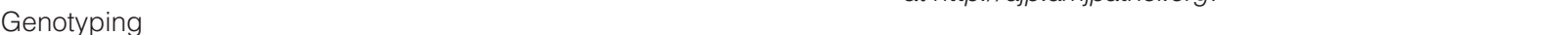 } \\
\hline IMR0135 (US) & $5^{\prime}$-CATCCCTGTGACCCCTCC-3' & $59^{\circ} \mathrm{C}$ & 151-bp fragment in C57BI6 Tg (Crh) mice. US primer \\
\hline IMR0136 (DS) & $5^{\prime}-$ СТССАААСCАССССССТC-3' & & $\begin{array}{l}\text { hybridises to human growth hormone } 3^{\prime} \text { UTR } \\
\text { sequence in transgene. DS primer is transgene- } \\
\text { specific. }\end{array}$ \\
\hline
\end{tabular}

ers, ${ }^{17}$ suggesting that acinar cells may also transdifferentiate into hepatocyte-like cells in vivo in response to elevated glucocorticoid.

The effects of elevated glucocorticoid exposure have therefore been examined in pancreata from a transgenic mouse that secretes elevated levels of endogenous glucocorticoid. We show for the first time that sustained chronic elevation of glucocorticoid sufficient to produce the signs of Cushing's syndrome results in extensive hepatocyte-like transdifferentiation in exocrine pancreas, exocrine dysfunction, and malabsorption.

\section{Materials and Methods}

\section{Animal Studies}

C57BI6 Tg(Crh) transgenic mice, originally generated by the laboratory of Vale et $\mathrm{al}^{18}$ (in which expression of the rat corticotrophin releasing factor under control of the mouse metalothionein promoter and human growth hormone 3' untranslated region results in elevations in circulating glucocorticoid), were obtained from the Jackson Laboratory (Bar Harbor, ME). Mice were housed in individually ventilated cages at stocking densities according to UK Home Office Codes of Practice, with sawdust bedding (Gold chip, BS and S Ltd, Edinburgh, Scotland) and nesting material (Shredded paper, DBM, Broxburn, Scotland). The animal rooms were maintained at $23^{\circ} \mathrm{C} \pm 1{ }^{\circ} \mathrm{C}, 48 \%$ humidity, and on a $12 / 12$ hour light/dark cycle (lights on at 07:00). Food (CRM (P), SDS Ltd, Essex, England) and water were provided ad libitum. Female adult mice were used in all studies (because only males could be used for successful mating with wild-type females) with genotypes checked by PCR using IMR0135 (US) and IMR0136 (DS) primers and conditions (see Table 1). All mice were on a C57BI6 background. The mice showed overt clinical signs of Cushing's syndrome within 15 weeks of age (eg, hair loss, obesity, thinning skin).

To test for glucose tolerance, mice were starved overnight for 9 hours before injection of $2 \mathrm{~g}$ glucose $/ \mathrm{kg}$ body weight by i.p. injection. Serum was prepared from tail vein bleeds just before and at various times after glucose injection. Insulin levels were determined using a murine insulin ELISA kit obtained from Millipore (Watford, UK). Glucose was determined by enzymatic assay as previously described. ${ }^{19}$

Some mice (between 8 and 10 weeks of age) underwent adrenalectomy or a sham procedure. Mice were anesthetized with isoflurane (5\% induction, 2-2.5\% maintenance) in $100 \%$ oxygen. Bilateral adrenalectomy, or a sham procedure, was performed using a dorsal approach. Buprenorphine $(0.1 \mathrm{mg} / \mathrm{kg}$ body weight $\mathrm{s} / \mathrm{c}$ ) and/or Meloxicam (5 mg/kg body weight s/c) was administered to provide postsurgical analgesia. Mice were allowed to recover in a warmed environment, and adrenalectomized mice were provided with a salt lick ad libitum.

Porcine pancreatic enzyme (Creon, Solvay) was added to powdered diet and provided to mice ad libitum at no more than 4000 units per mouse per day. The use of animals in this project was approved by the local Ethical Committee and the UK Home Office. 


\section{Immunohistochemistry}

Tissues were fixed in formalin and processed for immunohistochemistry as previously outlined. ${ }^{20}$ Antibodies were obtained from local commercial suppliers as previously reported ${ }^{17,20}$ except anti-cyp3a25, which was generously provided by Dr. Rob Edwards (Imperial College, London, UK).

\section{$R T-P C R$}

Total RNA was purified using Trizol (Invitrogen, Paisley, UK) and RT-PCR performed and analyzed as previously outlined (primer sequences are given in Table 1).

\section{Western Blotting}

Western blotting was performed as previously outlined ${ }^{20}$ with antibodies outlined as above. Detection was achieved using an ECL kit (Amersham, UK).

\section{Cell Isolation and Culture}

Rat hepatocytes were prepared by collagenase perfusion essentially as previously described. ${ }^{21} \mathrm{~B}-13$ cells were routinely cultured in Dulbecco's modified Eagle Medium (DMEM) supplemented with 10\% (v/v) fetal calf serum, 80 $\mathrm{u} / \mathrm{ml}$ penicillin, and $80 \mu \mathrm{g} / \mathrm{ml}$ streptomycin, under which conditions the cells remained proliferative and phenotypically stable. ${ }^{17,21}$ B-13 cells were subcultured using trypsin at a ratio of $3: 1$ by standard methods. ${ }^{17,21}$ All cells were incubated at $37^{\circ} \mathrm{C}$ in an humidified incubator gassed with $5 \% \mathrm{CO}_{2}$ in air. Dexamethasone (DEX), human corticotropin releasing hormone $(\mathrm{CRH}$, identical to rat sequence except for an additional N-terminal 3 amino acids), and adrenocorticotropic hormone $(\mathrm{ACTH}$, a truncated 1-24 peptide sequence conserved between human, rat, and mouse was used, which shows $85 \%$ activity of the full length peptide sequence) were all purchased from the Sigma Chem Co. (Poole, UK) and were added to medium from 1000-fold concentrated ethanol vehicle solvated stocks. Control cells were treated with ethanol alone.

\section{Statistics}

The Student's $t$-test (two-tailed) was used to test for replicate statistical significance.

\section{Results}

\section{Tg(Crh) Mice Show Symptoms of Chronic Elevated Systemic Glucocorticoid}

Endogenous glucocorticoid secretion is circadian and ultradian, which results in rapid changes in concentration in the circulating blood that is experimentally complex to model. To examine the effect of glucocorticoid on pancreatic differentiation pancreata from transgenic mice expressing rat $\mathrm{CRH}$ under control of the metallothionein-1 promoter were examined. These mice have high circulating glucocorticoid, ${ }^{18}$ and from around 15 weeks of age the $\mathrm{Tg}(\mathrm{Crh})$ mice showed overt signs of elevated circulating glucocorticoid, including thymic and splenic atrophy, alopecia, and reduced skin thickness (Figure 1 and data not shown). These mice therefore exhibit many of the clinical symptoms of Cushing's disease observed in humans.

Initial examination at 21 weeks of age showed that $\mathrm{Tg}(\mathrm{Crh})$ mice were obese (Figure 1A) with body weights significantly greater than age-matched wild-type animals (Figure 1B). The relative weights of several organs were significantly lower-most notably the pancreas, which was reduced by $64 \%$ in $\mathrm{Tg}(\mathrm{Crh})$ compared with wild-type mice (Figures 1, C and D). In contrast, relative liver weights were significantly increased in $\mathrm{Tg}$ (Crh) mice (Fig-
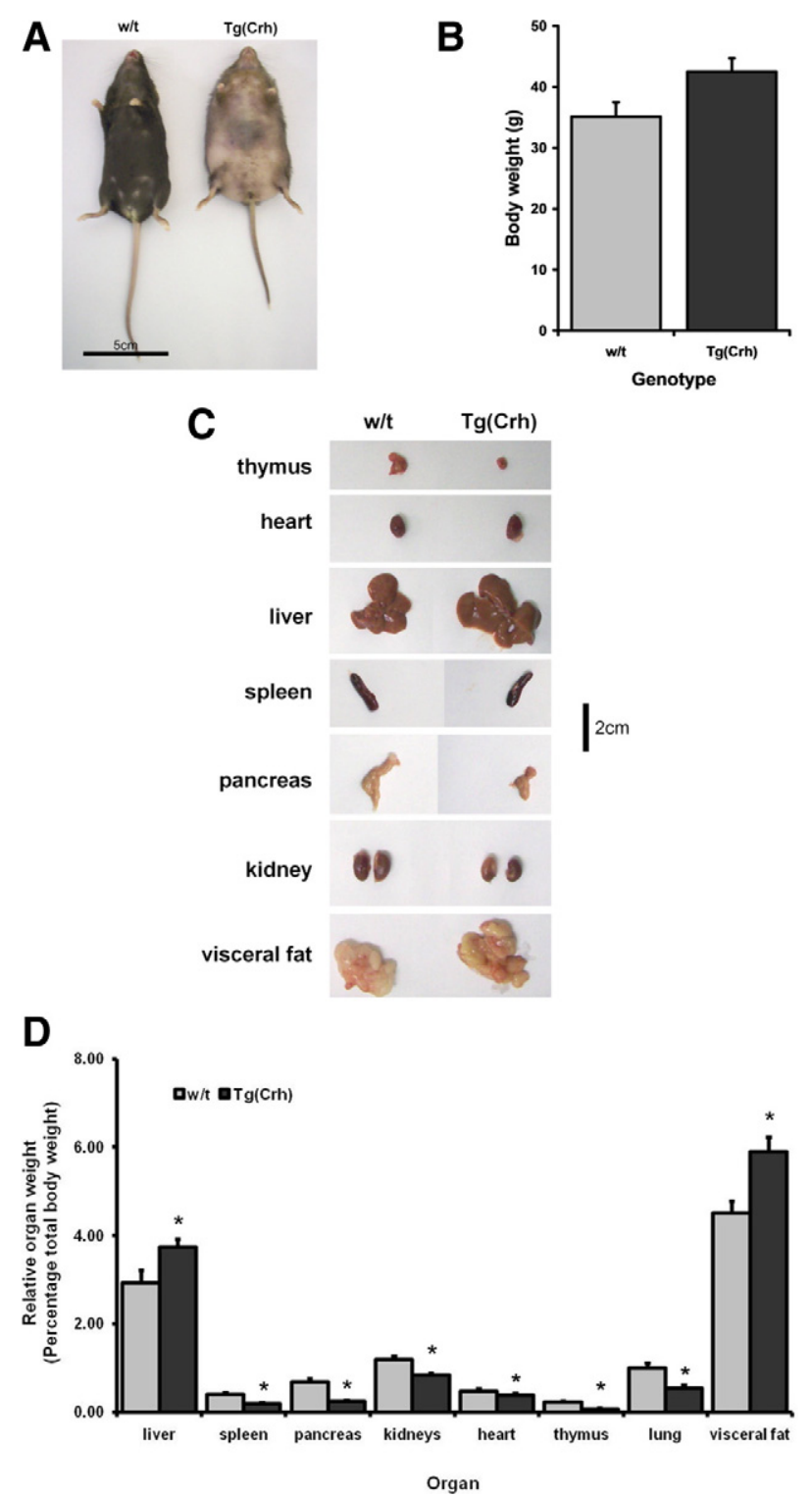

Figure 1. Gross effects of chronic elevated systemic glucocorticoid. Comparison of 21-week-old C57Bl6 wild-type (w/t) and C57B16 $\mathrm{Tg}(\mathrm{Crh})$ female mice (A), body weights $(\mathbf{B})$, dissected organs $(\mathbf{C})$, and relative organ weights (D). Data are the mean and SD determinations from at least three separate animals. Significantly different $\left({ }^{*} P<0.05\right)$ from wild-type using Students $t$-test (two-tailed). 
A

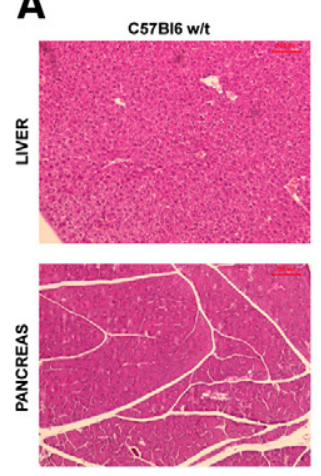

C

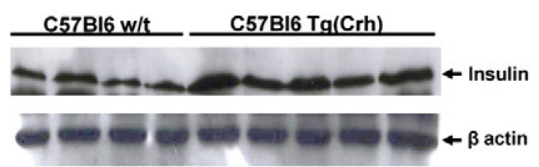

B

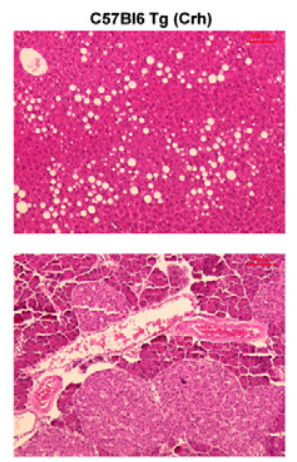

C57BI6 Tg(Crh)
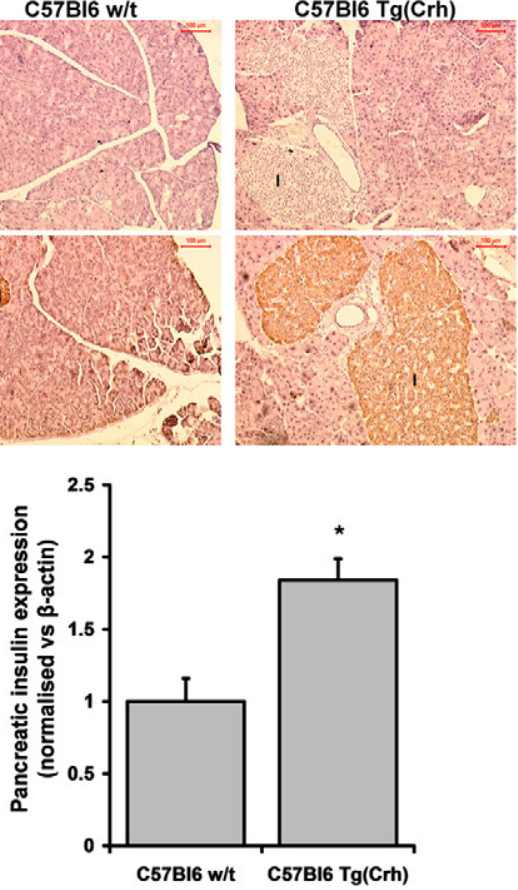

D

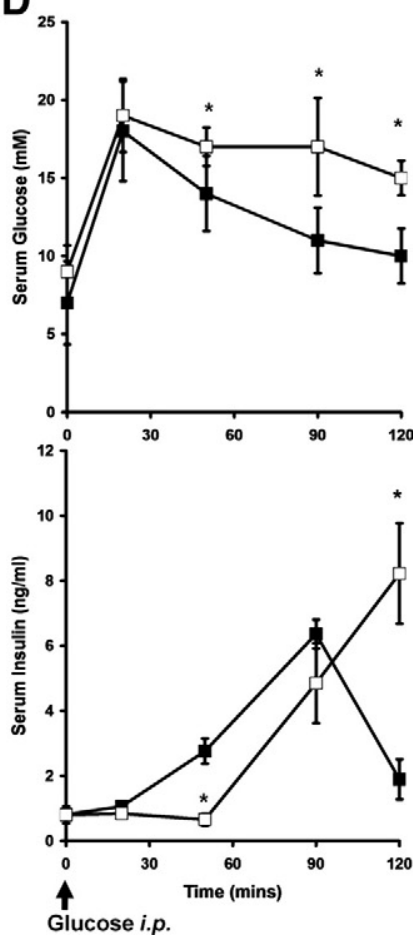

Figure 2. Hepatic and pancreatic changes in the $\mathrm{Tg}(\mathrm{Crh})$ mouse. A: Typical H\&E-stained liver sections from indicated mouse. B: Immunohistochemical staining for insulin expression in pancreas sections, no primary sections stained identically with the exception of incubation without primary antiinsulin antibody. C: Western blot for insulin levels from separate animals of the indicated genotype (left), and quantification using laser scanning software (right). D: Serum glucose (upper panel) and serum insulin (lower panel) in wild-type mice (closed box) or $\mathrm{Tg}(\mathrm{Crh})$ mice (open box) after injection of glucose at time indicated by arrow Data are the mean and SD of at least four separate mice, Significantly different $\left({ }^{*} P<0.05\right)$ from C57Bl6 wild-type using Student's $t$-test (two-tailed).

ure 1D), likely due in part to hepatic steatosis (Figure 2A). Relative visceral fat weight were also significantly increased in $\mathrm{Tg}(\mathrm{Crh})$ mice (Figure 1D).

Examination of pancreata in 21-week-old $\mathrm{Tg}(\mathrm{Crh})$ and wild-type mice showed that $\mathrm{Tg}(\mathrm{Crh})$ mice had significant pancreatic islet hyperplasia (Figure 2, A and B), a recognized response to high levels of glucocorticoids. ${ }^{22}$ Immunohistochemical staining of pancreata indicated that the islets from $\mathrm{Tg}(\mathrm{Crh})$ were positive for insulin (Figure $2 \mathrm{~B}$ ), indicating marked $\beta$ cell proliferation. Immunoquantification of insulin levels confirmed that the $\mathrm{Tg}(\mathrm{Crh})$ pancreas contained significantly more insulin (Figure 2C). Despite similar circulating glucose levels, there were significantly higher serum levels of insulin in unstarved $\mathrm{Tg}(\mathrm{Crh})$ mice (Table 2). Glucose tolerance tests showed that $\mathrm{Tg}(\mathrm{Crh})$ mice took longer to reduce the serum levels of glucose after i.p. injection of glucose (Figure 2D).

Table 2. Serum Glucose and Insulin Levels in Wild-Type and $\operatorname{Tg}(\mathrm{Crh})$ Mice

\begin{tabular}{lcc}
\hline \multicolumn{1}{c}{ Genotype } & $\begin{array}{c}\text { Serum glucose } \\
(\mathrm{mmol} / \mathrm{L})\end{array}$ & $\begin{array}{c}\text { Serum insulin } \\
(\mathrm{ng} / \mathrm{ml})\end{array}$ \\
\hline C57Bl6 wild-type & $7.0 \pm 0.31$ & $1.4 \pm 0.11$ \\
C57Bl6 Tg(Crh) & $6.8 \pm 0.42$ & $2.6 \pm 0.30^{*}$ \\
\hline
\end{tabular}

Blood was collected from 21-week-old mice by tail vein collection at 10:00 AM. Serum was prepared and analyzed as outlined in experimental section. Data are the mean and standard deviation of at least four animals per group.

${ }^{\star} P<0.05$ compared to wild-type using Students $t$-test (two-tailed).
$\mathrm{Tg}(\mathrm{Crh})$ mice were therefore insulin-resistant at 21 weeks of age.

\section{Widespread Age-Dependent Appearance of Hepatocytic Tissue in Acinar Pancreata from $\mathrm{Tg}(\mathrm{Crh})$ Mice}

To determine whether elevated circulating glucocorticoid affected acinar pancreatic differentiation, tissue sections from 21-week-old mice were initially screened for cyp2e1 expression. Figure 3A shows that pancreata from Tg(Crh) mice had widespread areas of acinar tissue that stained positive for cyp2e1, whereas the tissue was negative in wild-type mice. Islet cells have been reported to express some isoforms of cytochrome P450s. ${ }^{23}$ However, under the staining conditions used and by using liver as a positive control in all staining procedures, cyp2e1 expression was not detectable in islet tissue (eg, see Figure $3 \mathrm{~A}$, lower middle panel, also Figure 3B). Costaining tissue for amylase and cyp2e1 demonstrated that acinar tissue from $\mathrm{Tg}(\mathrm{Crh})$ mice stained positive for both markers but only for amylase in acinar tissue from wild-type mice (Figure 3B). Cells were isolated from $\mathrm{Tg}(\mathrm{Crh})$ and wild-type pancreata and costained for amylase and cyp2e1 expression to more effectively quantitate the number of pancreas cells staining positive for cyp2e1. Acinar cells from $\mathrm{Tg}(\mathrm{Crh})$ mice stained for either amylase only $(39 \pm 6.4 \%)$, or amylase and cyp2e1 (56 $\pm 7.6 \%)$. More rarely, acinar-like cells stained for cyp2e1 only. 
A
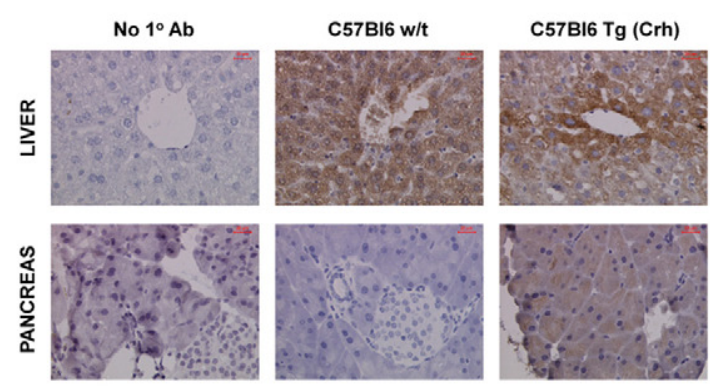

C

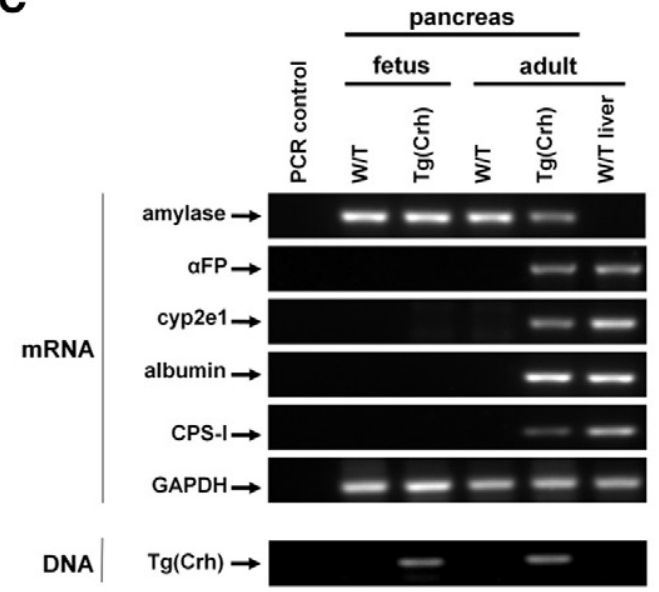

\section{B C57BI6 w/t}
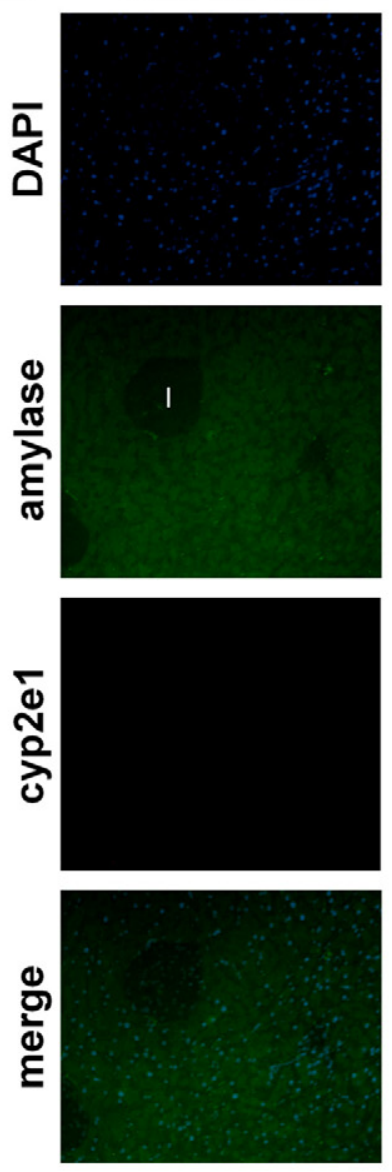

$\mathbf{F}$
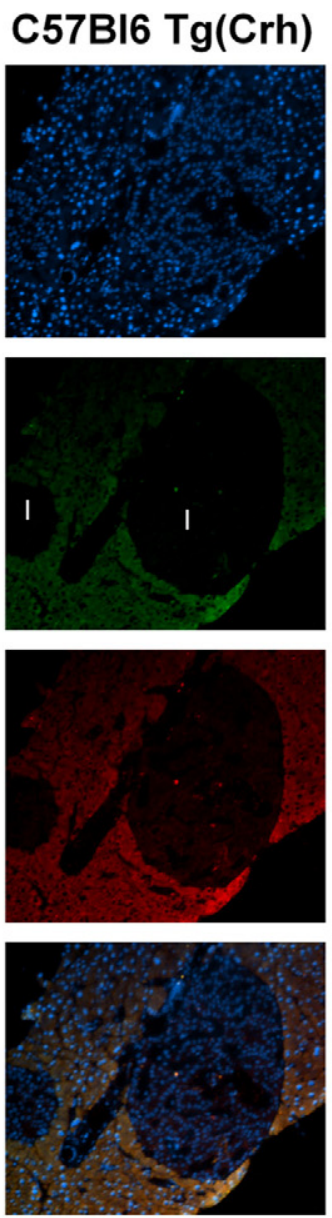

D

E
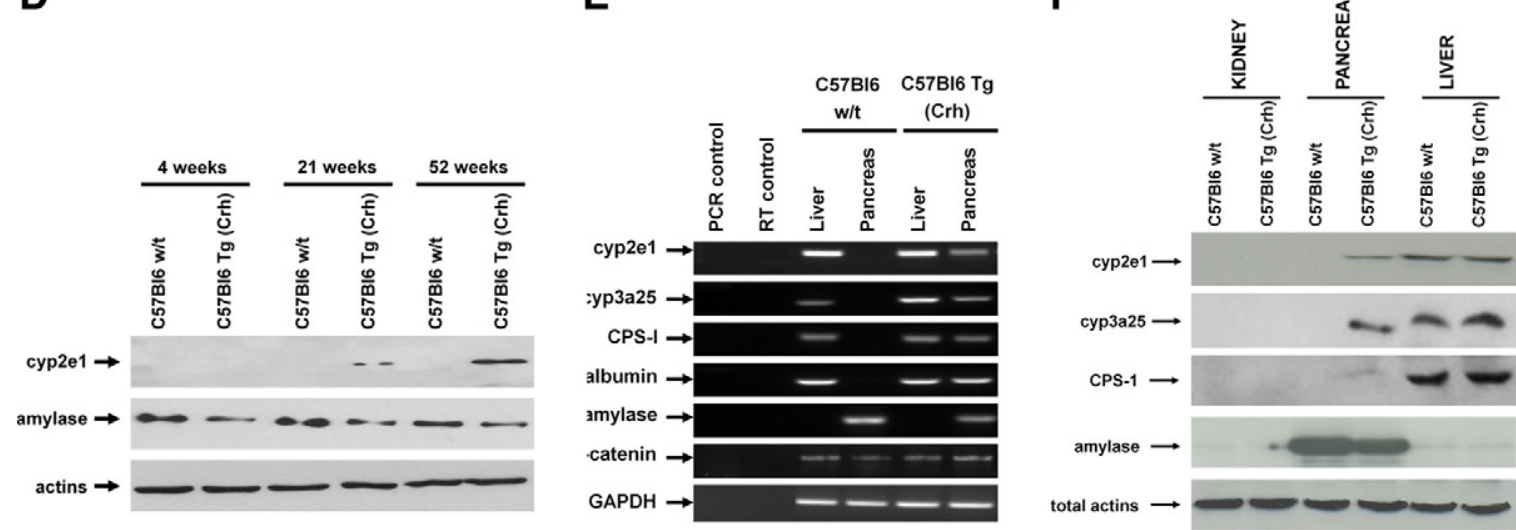

Figure 3. Widespread expression of hepatic markers in adult (21-week-old) $\mathrm{Tg}(\mathrm{Crh})$ mouse pancreas. A: Liver and pancreas sections from adult mice immunostained for cyp2e1. "No $1^{\circ}$ Ab," sections stained without the addition of the primary (CYP2E) antibody. B: Pancreata were costained for amylase (green) and cyp2e1 (red) and expression examined by fluorescence microscopy with DAPI staining (blue) to identify nuclei. No primary antibody staining was used as controls (not shown), and all microscope/software settings retained for all Figures. I, islet. C: Wild-type female mice were mated with male Tg(Crh) mice and fetuses harvested at approximately 14 days gestation. DNA was isolated from each fetus for genotyping (lower panel) and RNA was isolated from pancreata (and brain to check for transgene expression; see Table 1). Expression of the indicated transcript was determined by RT-PCR and compared with wild-type and Tg(Crh) pancreas and liver expression. D: Western blot of homogenized pancreata prepared from wild-type and $\mathrm{Tg}(\mathrm{Crh})$ mice at the indicated age. Twenty micrograms of total protein were loaded in each lane and expression for the indicated marker determined. E: RT-PCR analysis from RNA isolated from liver and pancreas tissues and screened for the indicated transcript-30 cycles for al samples. F: Western blot of homogenized tissues prepared from wild-type and $\mathrm{Tg}(\mathrm{Crh})$ mice. Twenty micrograms of total protein were loaded in each lane and expression for the indicated marker determined. Results for all panels are typical of at least four animals per time point and genotype.

Figure 3, C and D indicates that the appearance of hepatocyte-like cells in the pancreata of $\mathrm{Tg}(\mathrm{Crh})$ mice was an adult-specific response, because hepatic mRNA transcript expression was only observed in adult and not fetal $\mathrm{Tg}(\mathrm{Crh})$ pancreata (Figure 3C) and protein levels detectable only in $\mathrm{Tg}(\mathrm{Crh})$ pancreata from between 4 and 21 weeks of age (Figure 3D). The lack of hepatic gene expression in fetal pancreata occurred despite evidence 
of rat $\mathrm{CRH}$ transgene expression in fetal $\mathrm{Tg}(\mathrm{Crh})$ brain (see supplemental Figure 1 at http://ajp.amjpathol.org). The expression of cyp2e1 in $\mathrm{Tg}(\mathrm{Crh})$ pancreata therefore appears to be a response to long-term elevated glucocorticoid exposure in the adult.

Figure 3, E and $\mathrm{F}$ demonstrates that the appearance of hepatocyte markers in the pancreata from $\mathrm{Tg}(\mathrm{Crh})$ mice was not restricted to cyp2e1 but that a range of liverspecific and liver-enriched genes were detected at the mRNA level (Figure 3E) and protein level (Figure 3F). The quantitative nature of Western blotting supports the immunohistochemical data and demonstrates that a significant proportion of the $\mathrm{Tg}(\mathrm{Crh})$ pancreata were expressing hepatic levels of genes, and that the extent of exocrine pancreas transdifferentiation may have significant metabolic consequences.

\section{The Appearance of Hepatocyte-Like Cells in $\mathrm{Tg}$ (Crh) Pancreata Is Dependent on Elevated Glucocorticoid}

Adrenalectomising $\mathrm{Tg}(\mathrm{Crh})$ mice at $8-10$ weeks of age (before the appearance of liver marker gene expression in the pancreas) prevented the distinctive appearance (Figure 1A) seen with $\mathrm{Tg}(\mathrm{Crh})$ by 21 weeks of age (data not shown), the changes in relative organ weight (see supplemental Figure 2 at $h$ ttp://ajp.amjpathol.org), and the expression of hepatic markers in the $\mathrm{Tg}(\mathrm{Crh})$ pancreas (Figure $4 \mathrm{~A})$, indicating an absolute dependence on elevated glucocorticoid in vivo (and that the response is not associated with elevated rat $\mathrm{CRH}$ transgene expression or elevated ACTH expression). This observation is supported by the lack of response in the $\mathrm{B}-13$ pancreatic acinar cell line to $\mathrm{CRH}$ and $\mathrm{ACTH}$ hormones (Figure 4B). The B-13 cell transdifferentiates into hepatocyte-like cells in response to glucocorticoid exposure via suppression of WNT signaling activity and C/EBP- $\beta$ induction. ${ }^{1,21,24,25}$ Figure $4 \mathrm{~B}$ indicates that the B-13 cell responds to the glucocorticoid dexamethasone but not to $\mathrm{CRH}$ and $\mathrm{ACTH}$.

\section{The Appearance of Hepatocyte-Like Cells in $\mathrm{Tg}(\mathrm{Crh})$ Pancreata Is Associated with Malabsorption and Weight Loss as Animals Age}

As indicated in Figure 1, $\mathrm{Tg}(\mathrm{Crh})$ mice were obese and had significantly greater body weights at 21 weeks of age compared with age-matched wild-type mice. However, as $\mathrm{Tg}(\mathrm{Crh})$ mice aged, they began to lose weight, with a subpopulation (approximately $40 \%$, denoted as $\mathrm{Tg}(\mathrm{Crh})^{\star}$ ) losing body weight comparatively rapidly post 32 weeks of age (Figure 5A). Between 32 and 42 weeks of age of, both $\mathrm{Tg}(\mathrm{Crh})$ and $\mathrm{Tg}(\mathrm{Crh})^{\star}$ mice body weights were significantly lower than wild-type mice, whereas their weights were significantly greater or similar, respectively, at 32 weeks (Figure $5 \mathrm{~B}$ ). Figure $5 \mathrm{C}$ demonstrates that the relative levels of amylase expression in pancreata from $\mathrm{Tg}(\mathrm{Crh})$ mice were lower than the levels in wild-types and markedly lower in pancreata from $\mathrm{Tg}(\mathrm{Crh})^{\star}$ mice, which had lost the most weight. It was therefore hypothesized that body weight
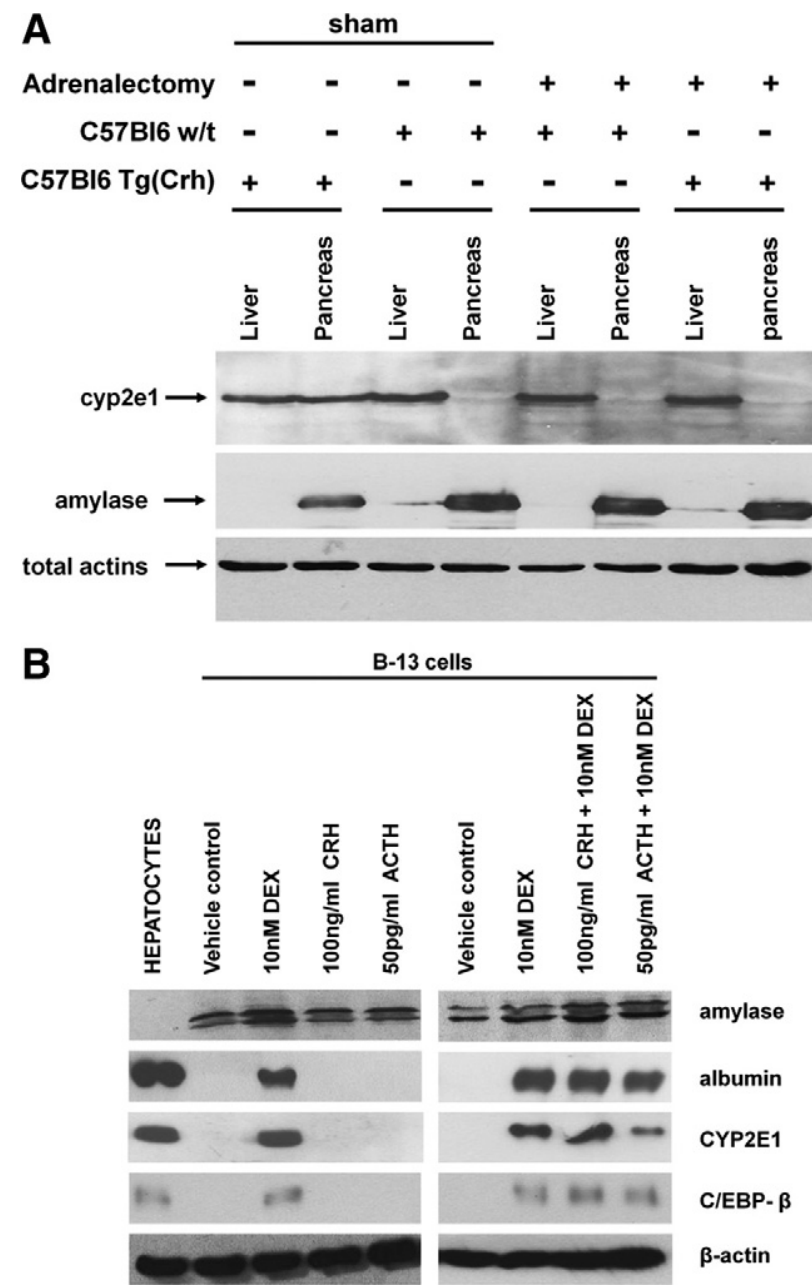

Figure 4. Transdifferentiation of B-13 cells and appearance of hepatocytelike cells in adult $\operatorname{Tg}(\mathrm{Crh})$ pancreata is dependent on glucocorticoid. $\mathbf{A}$ Western blot of homogenized pancreata prepared from 21-week-old wildtype and $\operatorname{Tg}(\mathrm{Crh})$ mice subjected to adrenalectomy at 8-10 weeks of age. Twenty micrograms of total protein were loaded in each lane and expression for the indicated marker determined. Results typical of at least three animals per genotype and treatment. B: Western blot of B-13 cells treated as indicated for 14 days and probed for the expression of the indicated protein. Results typical of at least three separate experiments.

losses in $\mathrm{Tg}(\mathrm{Crh})$ mice were associated with a loss of exocrine pancreatic function and reduced ability to digest and absorb nutrients from the gut. To test this hypothesis, mouse diet was supplemented with enteric-coated porcine pancreatic enzyme and body weights monitored for 40 days. Figure 5, D and $E$ supports the hypothesis of exocrine pancreatic dysfunction and malabsorption because wildtype animals (with functional exocrine pancreas) were not affected by pancreatic enzyme supplementation, whereas both $\mathrm{Tg}(\mathrm{Crh})$ and $\mathrm{Tg}(\mathrm{Crh})^{*}$ mice gained significant body weight.

\section{Discussion}

It has been known for some time that hepatocyte-like cells appear in the rodent pancreata in response to damage or ectopic expression of growth factors. ${ }^{1-4}$ This article demonstrates for the first time that this response also 
A

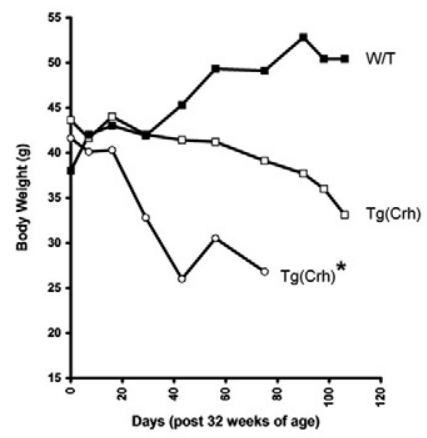

C

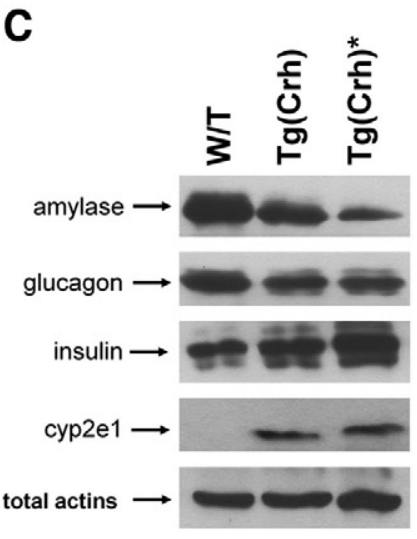

B

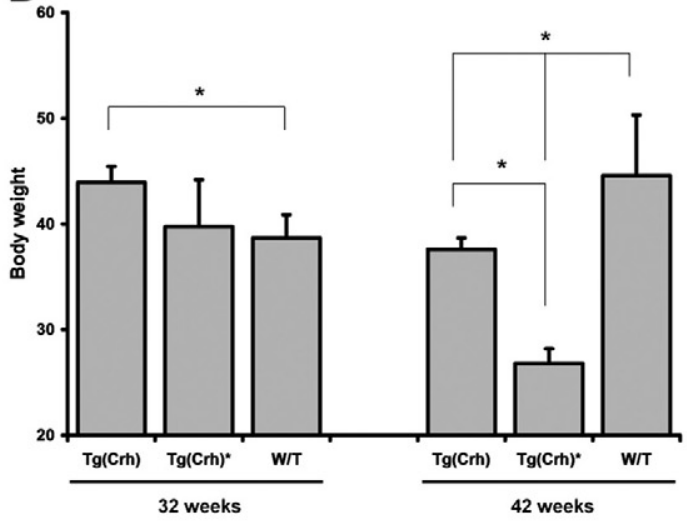

D

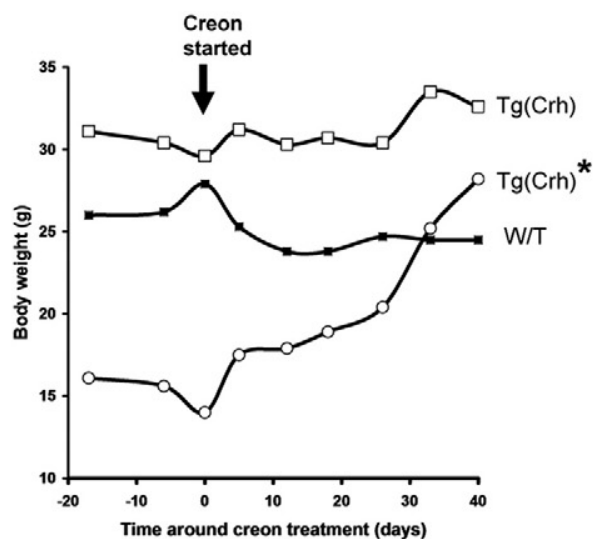

E

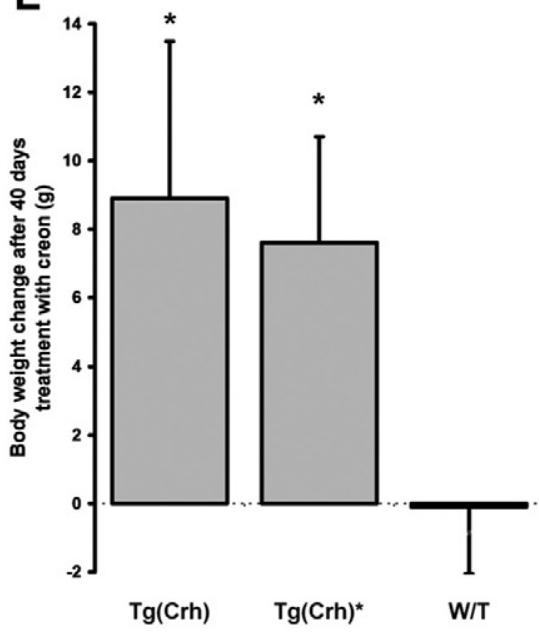

Figure 5. Appearance of hepatocyte-like cells in adult $\mathrm{Tg}(\mathrm{Crh})$ pancreata is associated with marked loss of exocrine function and malabsorption. A: Body weights for individual mice, wild-type (closed box) and $\mathrm{Tg}(\mathrm{Crh})$ (open box) mice, which showed the commonest time course for weight loss, Tg(Crh)* (open circle) mice which rapidly lost weight after approximately 32 weeks of age. B: Comparison of body weights (mean and SD of at least five animals per genotype) at 32 and 42 weeks of age. C: Western blot of homogenized pancreata prepared from the indicated mice at 10 months of age. Twenty micrograms of total protein were loaded in each lane and expression for the indicated marker determined, typical of at least three animals per genotype and phenotype. D: Typical body weight changes in the indicated mice before and after addition of creon to diet (as indicated by arrow). Data are typical of at least five mice per group. E: Bar graph of body weight changes in the indicated mice after 40 days of treatment with creon. Data are the mean and SD of at least five animals per group. Where indicated, significantly different body weight ${ }^{*} P<0.05$ using Student's $t$-test (two-tailed).

occurs in response to prolonged elevated glucocorticoid exposure and in the absence of any overt pancreatic damage. The primary theory proposed for the presence of hepatocyte-like cells in rodent pancreas is that a pancreatic progenitor cell-likely in the ductal regions-aberrantly differentiates into hepatocyte-like cells because the preceding tissue damage leads to an altered extracellular matrix and/or growth factor environment and subsequent misdirected differentiation of progenitor cells.

Short-term administration of glucocorticoid to rats gives rise to occasional acinar cells that stain positive for hepatic markers in pancreata with no evidence of pancreatic damage. ${ }^{17}$ However, this observation could be the result of a relatively rare response of little biological relevance. The widespread hepatic expression in $\mathrm{Tg}(\mathrm{Crh})$ pancreata demonstrate that this response is a common pathophysiological response to elevated glucocorticoid and therefore of both clinical interest (for patients maintained on long term systemic glucocorticoid therapy) and biological interest (because it demonstrates a role for glucocorticoid on cellular differentiation in vivo). The $\mathrm{Tg}(\mathrm{Crh})$ mouse model and rat glucocorticoid dosing model ${ }^{17}$ support the concept that hepatocyte-like cells are emerging primarily by transdifferentiation of acinar cells-hepatocyte-like cells appear in regions with no apparent associated ductal link and express both acinar (amylase) and hepatic (cyp2e1) genes. Indeed, the process in vivo appears to mirror the transdifferentiation of B-13 cells into hepatocytes in response to glucocorticoid, ${ }^{21,24,25}$ suggesting that the B-13 cell is modeling a pathophysiological response of acinar cells to glucocorticoid in vivo.

A common adverse side effect of glucocorticoid therapy is infection because of the antiinflammatory properties of steroids. A screen of Drug Analysis Prints [which list all UK spontaneous suspected adverse drug reactions reported through the Yellow Card Scheme to the MHRA and the UK Government's independent scientific committee on medicines safety, the Commission on Human Medicines (CHM)] between July 1, 1963 and November 26, 2009 indicates that the number of adverse events categorized as "metabolic" (eg, diabetes mellitus, diabetic complications, hyperglycemia, pancreatitis) for dexamethasone, betamethasone, and prednisolone occur at $60.0 \%, 50.0 \%$, and $36.3 \%$, respectively, as often as infection. The level of metabolic adverse effects to glucocorticoids is therefore significant within the context of adverse effects of glucocorticoids and exocrine trans- 
differentiation may be a significant, yet unrealized, contribution to this.

These data therefore predict that long-term systemic glucocorticoid therapy may have significant adverse effects on pancreatic exocrine function that may progress to malabsorption. This should be a consideration when clinicians are prescribing long-term systemic glucocorticoid therapy.

\section{References}

1. Rao MS, Dwivedi RS, Subbarao V, Usman MI, Scarpelli DG, Nemali MR, Yeldandi A, Thangada S, Kumar S, Reddy JK: Almost total conversion of pancreas to liver in the adult rat: a reliable model to study transdifferentiation. Biochem Biophys Res Commun 1988, 156:131-136

2. Yeldandi AV, Tan XD, Dwivedi RS, Subbarao V, Smith DD Jr, Scarpelli DG, Rao MS, Reddy JK: Coexpression of glutamine synthetase and carbamoylphosphate synthase I genes in pancreatic hepatocytes of rat. Proc Natl Acad Sci USA 1990, 87:881-885

3. Krakowski ML, Kritzik MR, Jones EM, Krahl T, Lee J, Arnush M, Gu D, Sarvetnick N: Pancreatic expression of keratinocyte growth factor leads to differentiation of islet hepatocytes and proliferation of duct cells. Am J Pathol 1999, 154:683-691

4. Yamaoka T, Yoshino K, Yamada T, Yano M, Matsui T, Yamaguchi T, Moritani M, Hata J, Noji S, Itakura M: Transgenic expression of FGF8 and FGF10 induces transdifferentiation of pancreatic islet cells into hepatocytes and exocrine cells. Biochem Biophys Res Commun 2002, 292:138-143

5. Makino T, Usuda N, Rao S, Reddy JK, Scarpelli DG: Transdifferentiation of ductular cells into hepatocytes in regenerating hamster pancreas. Lab Invest 1990, 62:552-561

6. Lemaigre F, Zaret KS: Liver development update: new embryo models, cell lineage control, and morphogenesis. Curr Opin Genet Dev 2004, 14:582-590

7. Zhou Q, Brown J, Kanarek A, Rajagopal J, Melton DA: In vivo reprogramming of adult pancreatic exocrine cells to beta-cells. Nature. 2008, 455: 627-32

8. Baeyens L, Bonné S, Bos T, Rooman I, Peleman C, Lahoutte T, German M, Heimberg H, Bouwens L: Notch signaling as gatekeeper of rat acinar-to-beta-cell conversion in vitro. Gastroenterology 2009 , 136:1750-1760

9. Lardon J, De Breuck S, Rooman I, Van Lommel L, Kruhoffer M, Orntoft $\mathrm{T}$, Schuit F, Bouwens L: Plasticity in the adult rat pancreas: transdif- ferentiation of exocrine to hepatocyte-like cells in primary culture. Hepatology 2004, 39:1499-1507

10. Munck A, Guyre PM, Holbrook NJ: Physiological functions of glucocorticoids in stress and their relation to pharmacological actions. Endocr Rev 1984, 5:25-44

11. Vinson GP: The adrenal cortex and life. Mol Cell Endocrinol 2008, 300:2-6

12. Ross AS, Cohen RD: Medical therapy for ulcerative colitis: the state of the art and beyond. Curr Gastroenterol Rep 2004, 6:488-495

13. Rutgeerts PJ: An historical overview of the treatment of Crohn's disease: why do we need biological therapies? Rev Gastroenterol Disord 2004, 4:S3-9

14. Barnes PJ: Efficacy of inhaled corticosteroids in asthma. J Allergy Clin Immunol 1998, 102:531-538

15. Thiele DL: Autoimmune hepatitis. Clin Liver Dis 2005, 9:635-646

16. Kirwan J, Power L: Glucocorticoids: action and new therapeutic insights in rheumatoid arthritis. Curr Opin Rheumatol 2007, 19:233-237

17. Wallace K, Marek CJ, Currie RA, Wright MC: Exocrine pancreas trans-differentiation to hepatocytes-a physiological response to elevated glucocorticoid in vivo. J Steroid Biochem Mol Biol 2009, 116:76-85

18. Stenzel-Poore MP, Cameron VA, Vaughan J, Sawchenko PE, Vale W Development of Cushing's syndrome in corticotropin-releasing factor transgenic mice. Endocrinology 1992, 130:3378-3386

19. Haughton EL, Tucker SJ, Marek CJ, Durward E, Leel V, Bascal Z, Monaghan T, Koruth M, Collie-Duguid E, Mann DA, Trim JE, Wright MC: Pregnane $X$ receptor activators inhibit human hepatic stellate cell transdifferentiation in vitro. Gastroenterology 2006, 131:194-209

20. Marek CJ, Tucker SJ, Konstantinou DK, Elrick LJ, Haefner D, Sigalas C. Murray GI, Goodwin B, Wright MC: Pregnenolone-16alpha-carbonitrile inhibits rodent liver fibrogenesis via PXR (pregnane $X$ receptor)dependent and PXR-independent mechanisms. Biochem J 2005, 387:601-608

21. Marek CJ, Cameron GA, Elrick LJ, Hawksworth GM, Wright MC Generation of hepatocytes expressing functional cytochromes P450 from a pancreatic progenitor cell line in vitro. Biochem J 2003, 370:763-769

22. van Raalte DH, Ouwens DM, Diamant M: Novel insights into glucocorticoid-mediated diabetogenic effects: towards expansion of therapeutic options? Eur J Clin Invest 2009, 39:81-93

23. Ulrich AB, Standop J, Schmied BM, Schneider MB, Lawson TA, Pou PM: Species differences in the distribution of drug-metabolizing enzymes in the pancreas. Toxicol Pathol 2002, 30:247-253

24. Shen CN, Slack JM, Tosh D: Molecular basis of transdifferentiation of pancreas to liver. Nat Cell Biol. 2000, 2:879-887

25. Wallace K, Marek CJ, Hoppler S, Wright MC: Glucocorticoid-dependent trans-differentiation of a pancreatic progenitor cell to hepatocytes is dependent on a transient suppression of WNT signaling J. Cell Science 2010, 123:2103-2110 